blinded by an eagerness to assign inferior quality to female cells, genes or brains.

The book's final section asks the question: will feminist scientists change science? Well, in some areas of science they already have, for instance in animal behaviour studies, Earth sciences and medical research. Hilary Rose, who has been chosen to provide an uplifting epilogue, sees "harbingers of hope". I agree. An increasing number of men love science enough not to deprive it of the "brilliance of women" (Rose). In the United States, where women complain more loudly than in most other countries, equal-opportunities policies have improved their lot in publicly funded research. But in Europe, according to "Women and Science", a report published last year by the European Technology Assessment Network, even countries committed by European treaties to fight discrimination in the work-place are reluctant to interfere with scientific bodies. If they don't interfere with teamsters' unions or soccer fans, who cares? But scientists take pride in their objectivity, yet don't notice that their sexist bias makes them look like the Victorians who preached family values to the underclass during the day and patronized brothels at night. No wonder so many women still think, with Virginia Woolf, that science "is a man, a father, and infected too".

Sylvie Coyaud is a science journalist based in Milan(e-mail:scoyaud@planet.it).

\section{Nothing to it!}

\section{The Book of Nothing}

by John D. Barrow

Pantheon: 2001. 370 pp. $\$ 27.50$

\section{John O'Connor}

It must have been all those noughts at the end of last year's date that started people writing about zero. In 1999 we had Robert Kaplan's The Nothing That Is: A Natural History of Zero (Penguin), in 2000 we had Charles Seife's Zero: The Biography of a Dangerous Idea (Souvenir), and now we have John Barrow's The Book of Nothing. It's like standing at a bus stop. For 1,000 years nothing arrives and then you get three books on zero coming along together.

Kaplan's book was content to examine the history of zero and its position in a mathematical framework. The other two take the exploration of the idea out of the domain of pure mathematics and into the modelling of the physical Universe. This makes for a livelier story and expands the interest of the topic away from the purely arithmetic. Of these two, Barrow's book is the more authoritative and tells the story more persuasively. As with all popular books on modern physics, the

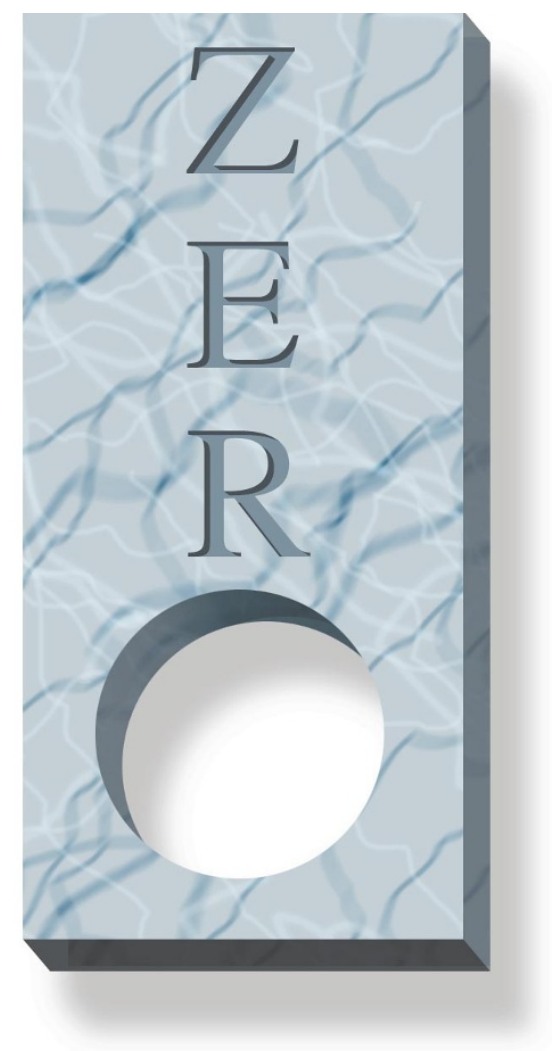

empty set. It is the true universal concept. No wonder that this idea, which mathematicians now accept with equanimity, caused much debate and heart-searching down the centuries among philosophers and theologians.

Early scientists, despite the reservations of the philosophers, pursued the vacuum increasingly successfully with their barometers and pumps, and the idea of an empty space seemed eminently satisfactory. But then the necessity of finding a medium to allow the propagation of various electromagnetic waves meant that theoreticians were led to fill it up again with a presumed 'ether' an invisible, inviscid fluid permeating all space. Physicists played intricate games with this new toy. Lord Kelvin and Peter Tait knotted ethereal vortices; Simon Newcomb and John Gore invoked its properties to explain the darkness of the night sky. Theologians likened it to "The Rudder of the Universe, the Rod ... in the Hand of the Almighty".

With the benefit of hindsight, we can see that by the end of the nineteenth century the theory was running into trouble. This was the beginning of big-money science, and it was the first telecom magnate, Alexander Graham Bell, who financed the experiments that laid the ether to rest. Albert Michelson and Edward Morley found strong evidence for its non-existence, and eventually the man-in-the-street's favourite eccentric genius, Albert Einstein, devised a theory that allowed it to be dispensed with altogether and so restored the status quo for an empty vacuum. It was a pity he had to use mathematics that the man-in-the-street could not possibly understand.

Nature may not always abhor a vacuum, but theoretical physicists seem unable to leave it alone. Only a short time after Einstein had restored empty space as a concept that one could believe in, the invention of quantum mechanics made it something that was too simple to satisfy the new theories. In the most persuasive model, any so-called empty box contains innumerable pairs of virtual particles which switch themselves in and out of existence, and which contribute to the energy of that apparently empty hole. This is the zero-point or vacuum energy. Even the experimentalists joined in, and measured the tiny forces involved in the Casimir effect, one of its consequences. Barrow brings this firmly into the realms of credibility by outlining results on a nautical phenomenon noticed in the nineteenth century, when two ships wallowing near each other in a choppy sea were moved towards each other by the wave action. It turns out that this involves the same theory, albeit on a much greater scale.

Such is the way that modern physics is interconnected that these effects noticed in the 'quantum vacuum' turn out to have wide-ranging consequences even at the truly astronomical scale. Cosmologists now have to take account of this new version of empty 
space. Theories of how the Universe evolved in the first few moments after the Big Bang can be profoundly influenced by this concept of energetic nothingness.

In 1992, John Barrow wrote Theories of Everything: The Quest for the Ultimate Explanation (Clarendon). It is curious that a decade later the ultimate questions can be explored from the point of view of nothingness rather than everything.

John O'Connor is in the School of Mathematics and Statistics, University of St Andrews,

St Andrews KY16 9SS, UK.

\section{Dispelling the boredom}

Stimulating Concepts in Chemistry edited by Fritz Vögtle, J. Fraser Stoddart \& Masakatsu Shibasaki

Wiley-VCH: 2001. 414 pp. \$50, £29.95

The New Chemistry: A Showcase for Modern Chemistry and its Applications

edited by Nina Hall

Cambridge University Press: 2000. 493 pp.

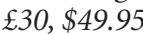

\section{G. M. Whitesides}

Each discipline in natural science has a popular reputation. Biology concerns itself with life and is intrinsically fascinating; physics does something very difficult and unfamiliar; astronomy looks at far-away objects and provides amazing pictures; chemistry makes paint and is boring. For those of us who know and love chemistry, this last view is a painful one. Our opinion is quite the opposite: that everything that one touches or sees or tastes is chemistry - that, in fact, all of perceptible reality involves conversations among atoms and molecules - and that an appreciation of chemistry is an essential and endlessly engaging component of an appreciation of the world.

Occasionally, groups of us gather our strength and try to explain why it is that molecules, and their behaviours and idiosyncrasies, are so fascinating. These two books are the fruits of such endeavours. Although both books are efforts to 'explain' chemistry, they have different scopes and styles. Both succeed - in the style of many multi-authored collections - by assembling a collage rather than painting a picture. In looking at a collage, of course, what you see depends on how far back you stand. And in a collage, although the edges can be rough and colours missing, there is often a sense of vigour. Both books convey that sense of vigour for chemistry.

Stimulating Concepts in Chemistry is exclusively focused on organic chemistry and its borders with neighbouring fields, especially biology, materials science and chemical engineering. Its chapters are in the style of reviews in technical journals, rather than essays intended to give a broader view. It is not concerned with the philosophy of its subjects - more with their nuts and bolts.

Organic chemistry is currently in a phase of change and expansion. For a number of decades, it has been focused on the art of organic synthesis. Its accomplishments in developing synthetic pathways to natural products - the often staggeringly complex molecules that are the odd offspring of metabolism - have been some of the great triumphs of the discipline. The utilitarian rationale for this area of research was that it developed methods that made possible the synthesis of drugs, as indeed it did. It was also intellectually very interesting — a grand game of strategy and logistics.

It is striking that very little of this classical genre is represented in these chapters. Their authors instead represent four different groups striking out across the marches. One develops synthetic methods - that is, refines important classes of reactions or processes - and traffics across the busy border between chemistry and chemical engineering. A second designs and fabricates organic molecules possessing new kinds of function: as wires for conducting electrons, molecular-scale machines, antennae for collecting light or molecular sponges that selectively adsorb other molecules. The authors of these chapters are collectively in the vanguard of those who believe that chemistry is a natural centre for nanoscience, as molecules are, in fact, exquisitely engineered and eminently manufacturable nanostructures.

A third group focuses on the synthesis of molecules relevant to biology. The molecules they describe mimic, inhibit or modify enzymes - all of these are activities that will be increasingly important as biology turns from cataloguing the genome to understanding the proteins whose structures it encodes. A fourth group simply makes new structures - exotic constructions containing only carbon atoms, multiply branched and rebranched molecules called dendrimers, and molecular crystals with designed structures. Chemists have always enjoyed making new molecules, and these chapters are baby pictures of new members of the molecular family.

The New Chemistry is a quite different book, and is intended, I think, for a more centrist audience. It is more classical in its coverage: it has a broader scope within chemistry and includes more history, but is less concerned with trade at the borders between chemistry and other disciplines. Its contributions span the full range of atomic and molecular behaviour: from the search for new elements to the production of energy, and from discussions of the nature of metals to discussions of chaos. It is surprisingly unconcerned with the intersection of chemistry and biology.

Is its title, New Chemistry, an accurate description? Well, yes and no. The fact that the essays cover a wide range of topics suggests, accurately, that the traditional subfields of chemistry are amalgamating. Some of the subjects - the chemistry of compounds held together by weak physical interactions rather than by covalent bonds, molecular electronics, materials, the production of energy, processes far from equilibrium, surfaces are probably all, for different reasons, in for long runs. Others, such as the synthesis of complex organic structures, the study of the chemical bond and the chemistry of inorganic ions, are so fundamental that they will certainly always be part of the field, but may not be where most of the students go. The virtual absence of contributions from areas such as biochemistry and environmental chemistry reflects the fact that every collage is made with the materials available, and some colours and textures are always missing.

So neither book provides a broadly accessible, poetic view of chemistry. Both require

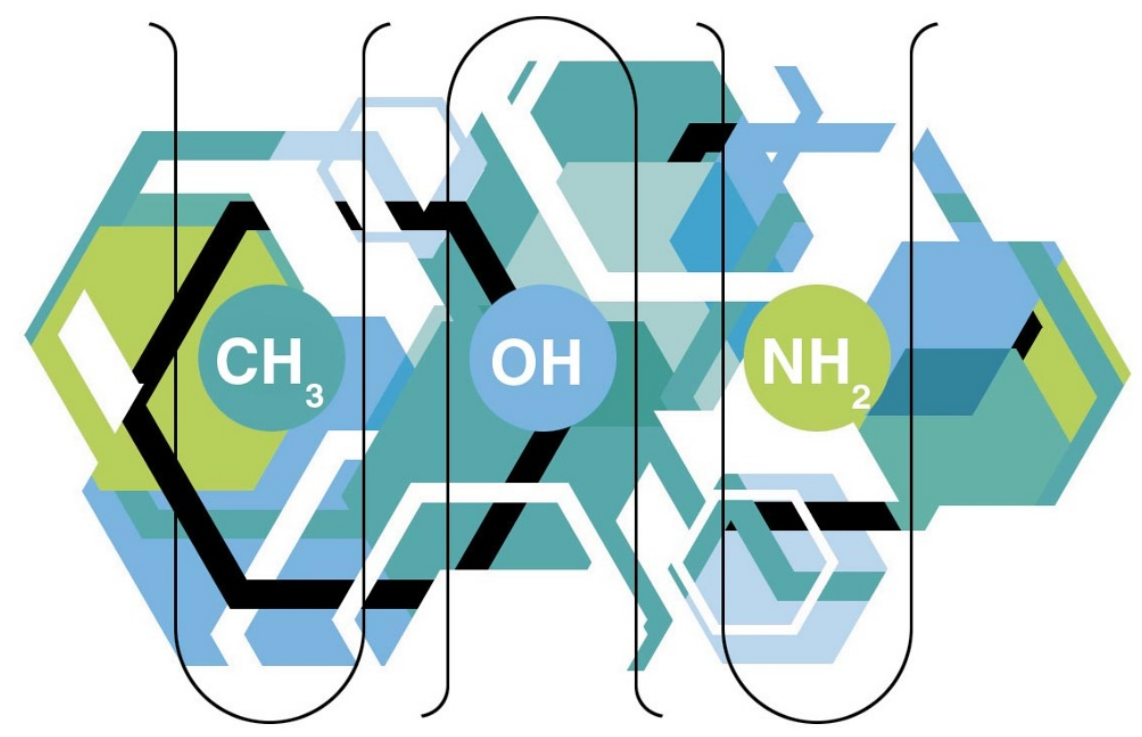

^ ๔ 2001 Macmillan Magazines Ltd 